MATHEMATICA, 63 (86), $\mathrm{N}^{\circ}$ 2, 2021, pp. 297-302

\title{
STRONG REGULARITY OF SMASH PRODUCTS ASSOCIATED WITH $G$-SET GRADINGS
}

\author{
GABRIELA OLTEANU
}

\begin{abstract}
For a group $G$, a $G$-graded $\operatorname{ring} R$ and a finite left $G$-set $A$, we study the strong regularity of the smash product $R \# A$.
\end{abstract}

MSC 2010. 16E50, 16D90, 16W50.

Key words. Strongly regular ring, smash product, $G$-set grading.

\section{REFERENCES}

[1] R.F. Arens and I. Kaplansky, Topological representations of algebras, Trans. Amer. Math. Soc., 63 (1948), 457-481.

[2] S. Crivei and A. Kör, Rickart and dual Rickart objects in abelian categories, Appl. Categor. Struct., 24 (2016), 797-824.

[3] S. Crivei and G. Olteanu, Strongly Rickart objects in abelian categories. Applications to strongly regular and strongly Baer objects, Comm. Algebra, 46 (2018), 4426-4447.

[4] S. Dăscălescu, C. Năstăsescu, A. Tudorache and L. Dăuş, Relative regular objects in categories, Appl. Categ. Struct., 14 (2006), 567-577.

[5] L. Dăuş, C. Năstăsescu and M. Năstăsescu, Von Neumann regularity of smash products associated with $G$-set gradings, J. Algebra, 331 (2011), 46-57.

[6] G. Lee, S.T. Rizvi and C. Roman, Modules whose endomorphism rings are von Neumann regular, Comm. Algebra, 41 (2013), 4066-4088.

[7] C. Năstăsescu, Ş. Raianu and F. Van Oystaeyen, Modules graded by G-sets, Math. Z., 203 (1990), 605-627.

[8] G. Olteanu, Strongly relative regular modules and excellent extensions of rings, Mathematica, 59 (82) (2017), 76-80.

[9] J. von Neumann, On regular rings, Proc. Natl. Acad. Sci. USA, 22 (1936), 707-712.

Received February 8, 2020

Accepted June 10, 2020
Babeş-Bolyai University

Department of Statistics-Forecasts-Mathematics

Str. T. Mihali 58-60

400591 Cluj-Napoca, Romania

E-mail: gabriela.olteanu@econ.ubbcluj.ro

DOI: 10.24193/mathcluj.2021.2.14 